\title{
POSITIVE AND NEGETIVE ROLE OF BIOTECHNOLOGY IN HUMAN LIFE: A REVIEW
}

\author{
Chavre B. W. \\ Arts, Commerce and Science College, Nandgaon, Dist. Nashik (M.S.), India. \\ ${ }^{*}$ Corresponding Author: chavrebhagwat@gmail.com
}

\author{
Communicated : 13.02 .2020
}

Revision : 15.03.2020 \& 27.4.2020

Accepted : 15.05 .2020

Published: 30.05 .2020

\begin{abstract}
:
Biotechnology contributed with a wide spectra in human life. The fields like agriculture, medicine, diagnosis, textile, food, environment and many more are highly captivated by various deliberating inventions of biotechnology.Advancement in it could led to the development of cellular engineering, biomaterials, biochips, stem cells, gene engineering and so proceeding rapidly.Due its interdisciplinary nature, it has progressed in all possible branches and have spread wings at social, political, economical, environmental and global levels.In a directive to meet needs of fast growing population, biotechnologists are oftenly engaged in the new invention in various grounds of biology.In some extent, we could achive our goal but some unidrectional and unpredicted experiments of biotechnology triggered some antagonistic and unexpected effects too. Evolution of novel microorganisms leading to new disease, side effects of GM foods, troubling ecological balance, loss of natural gene combinations, developed resistance by pests etc are some ill effects of biotechnology. In the present article, an attempt and approach is made to discuss some positive and negetive implications of biotechnological inventions so, that common people can get awared of everything they using for their livelihood. It is expected that, in the near future we should control some harmful trials and accelerate some fruitful investigations by taking care of welfare of human being and surroung environment.
\end{abstract}

Key words: - Positive, Negetive, Biotechnology, Environment, GM Foods, Bioplastic

\section{INTRODUCTION:}

Biotechnology, an interdisciplinary branch of biology could successfully make a way in different modern inventions. It involves the utilization of living things like cells and bacteria for production of various products of plant and animal origin for the wlefare of human being. It has the combinations of not only biology but mathematics, physics, chemistry, engineering and so many other disciplines. Now a days, biotechnology and its applications ranges from agriculture, medicine, plant physiology, antomy, seed technology, textile, food, nutrition, pharmaceuticals etc. Modern biotechnology is more progressive and advanced thant the old was. Different inventions took place till today could combat rare diseases, controlled environmental pollution, meet hunger, and safer and cleaner industrial manufacturing processes. The fields like genetic engineering, tissue culture, cloning, disease diagnosis, gene therapy, monoclonal antibodies and so on are the wonderful inventions revolutionised the world.Biotechnology has some drawbacks too like uncertainty, costs of the products, and some etical issues regarding clonning, xenotransplantation, stem cell research etc. In the present article, author has made an attempt to review some positive and negetive implications of biotechnology.

\section{POSITIVE ROLE OF BIOTECHNOLOGY}

Expansion of world population and fulfillment of all food related needs of human being is the main need of GM foods. Decrease in fertile land due to many manmade calamities like, urbanization, industrilization is main reason of decrease in food production which can be recovered by the use of high yielding genetically modified foods. Conventional 
breeding has some loopholes which can be filled by advanced techniques used in genetically modified foods. By keeping above needs in mind GM foods have been developed by using some advanced methods including direct DNA transfer and editing of genomic DNA. The data provided in the article reveals that, GM foods increased food production up to 370 million tons during 1996 to 2012. From 2006 to 2012 , the global farm income also increased up to 116 billion dollars Chen Zhang et. al. (2016). This increase in production and income is due to the advanced genetics and resistance to pests and weeds. It is evident that, GM food not only increased the quantity, but it has improved quality of the food. Chemical composition of foods like vitamins, fatty acids, celluolse etc also enhanced in GM foods as compare to natural foods ( Key et. al., 2008).

GM foods can also revolutionised the food processing. By some genetic changes in tomato, potato and othe food crops, scientists could make insect resistant crops expressing the bt gene from Bacillus thuringiensis and also improved shelf life and attractiveness in food materials. It is also achieved in animals especially fishes by improving the growth and body mass.For instance genetically modified fish Salmon have the natural full size growth period is 3 years rather GM fish grow fully in 18 months. GM foods also enriched with some therapeutic bacterial and viral antigens, so they may be serve as oral vaccines. (Chen Zhang et. al., 2016, Key et. al., 2008).

Biotechnologists, throughout the world has gentically modified varieties of many food plants like tomato, potato, tobacco, maize, soybean, golden rice and papaya. These plants shows some characters like insect resistance, stronger crops, larger production, environmental protection through minimising green house gas emission, crop protection from diseases, more nutritious foods, Decreased use of pesticides, more income and less deforestation by increased crop production and decrease in food price (Mathur, 2018).

Apart from their, above suses GM plants are aslo being assessed for the selective removal of pollutants from the soil- a process known as phytoremediation. Plants are genetically engineered to accumulate heavy metal contaminants of the soil such as mercury and selenium. These plants can be grown on the contaminated sites, harvested and destroyed, the heavy metals disposed of or recycled and the decontaminated field can be reused to grow other crops (Key et. al., 2008).A review was published by Wim and Erick (2006) on impact of industrial biotechnology and its applications. In this context, they expected a transition from a fossil- based to a bio-based economy and society. The new biotechnology refers to green chemistry in which renewable resources such as sugars or vegetable oils are transformed into a wide variety of chemical substances like pharmaceuticals, biocolourants, bioplastics, vitamins and food aditives. Also industrial biotechnology is used to produce a wide variety of bulk and fine chemicals alike alcohol, lactic acid, citric acid, amino acids, solvants, antibiotics, flavours and aroma, biopolymers, bio-surfactants, alkaloids, bioplastics, steroids etc.Genetic engineering has been applied for many crop plants as well as for many trees that are propagated in the forsests. Advantages and disadvantages of plant genetic engineering is remained a centre of public debate. Mathews and Campbell (2000), in their comprehnsive review discussed son advantages and disadvantages of genetically engineered trees. Inappropriate transgene may convert plants into a weed that may be harmful for a ecosystem. So, gene transfer should be done 
by desirable traits in forest trees. The first group of genes govern agronomic traits i.e. vigour, resistance to pests and diseases and resistance to environmental stresses. The second group of genes govern traits that improve production, efficiency, product quality and product value i.e. genes that render wood for paper making and for construction purposes. The The first genetically engineered tree was Populus sp. which carrying gene for herbicide resistance gene like Roundup Ready. This is the great success of genetic ingineering which facilitated weed control during silviculture management of poplars. This experimen leds to incresed herbiside pollution and checks soil erosion as well as Poplars could successfully compete weeds for water, soil, nutrients and sunlight. Genetic engineered forest trees are also pest resistant due to their improved defence mechanism. Such trees do not need external used of pesticides which is unaccepted due to environmental and financial reasons. The transgene coding for toxin from bacteria Bacillus thuringiensis for such gentic engineering programme. Other advantages of genetically engineereed forest trees are improved timber quality and density, modified lignin content etc.Food biotechnology is an emerging branch of biotechnology in which taste, shell life, nutrition and quality of food have been enhanced. GM yeasts and bacteria are used to produce enzymes for the sake of food industry. Haroon and Mobeen (2016), have enumerated some applications of food biotechnology including fermentation, use of enzymes, improvement of food nutrition, yield, enhance the taste. Yeast is the most significant and easily available source for fermentation. Genetically modified yeast is used in production of light wine by the conversion of glucose in to alcohol.Enzymes like, a-amylase, protease, catalase, glucose oxidase, rennin derived from various fungi and bacteria are used in the production of different foods products. In order to enhance the nutrition with respect to vitamins and minerals, iron, carbohydrates and lipids of our staple foods genetic engineering of some crops like rice, potato has been carried out. The gene coding for hormone bovine somatotropin is derived from Escherichia coli is inserted in the lactating animals could increase 10-12\% milk production. Agriculture biotechnology is the area of biotechnology involving applications to agriculture. Biotechnologists, throughout the world have concentrated on the enhancement of agricultural produce through genetic manipulation and genetic modifications. Ania (2003) in his findings putforth some advantages of agricultural biotechnology. Increased crop productivity, enhnaced crop protection, improved food processing and nutritional value are some of the applications of implementing biotechnology in agriculture. The genetic engineering has allowed to identify and to isolate specific genes of the DNA in the donating organism by means of restriction enzymes that acts as 'chemical scissors'. This practice is very important to make agricultural crops more resistant to stresses and diseases, and enhancing the protein, oil and amino acid contents so as to enhance nutritious properties of fruits and grains (Sanchez and Maria, 2003).Petroleum based conventional plastic created various environmental issues like green house gas emission, littering and non-degradable waste generation (Ibrahim et.al., 2017). To conquer these problems, biotechnologists has discovered a new typeof plastic known as bioplastic. Bioplastics can be classified into different classes viz. Bio-based, Bio-degradable and Biobased and biodegradable. Biobased bioplastics are made from some renewable resources like starch, sugarcane, hemp etc. which emits very less 
carbondioxide and ecofriendly e.g. Polyethylene and Polyamide. Biodegradable is another class of bioplastics which automatically degrades in the environment without any additives and can be used for one time packaging. For example, Poly- butyrate adipate- terphthalate (PBAT), PolyCaprolactone (PCL). Poly lactic acid (PLA) and Polyhydroxylalkanoates (PHA) are Bio-based and biodegradable type of bioplastics. .(Pankaj kumar and Sonia, 2016) All these different types of bioplastics have some advantages over the conventional plastics. They includes unlimited raw material, biodegradable in nature hence ecofirndly, requires less energy for prodcution, requires less dependancy on foreign oil and nontoxic in nature (Ezgi and Havva, 2015). These bioplastics are now being used in food industry, for water bottles and fruits packaging, in cosmetic industry for different type of beauty product preparation and packaging, Pharmaceutical industry for making gloves, tablete strips, etc and in automobile industry for the preparaion of parts of car.(Pankaj kumar and Sonia, 2016).Among the widely used bio-plastics poly lactic acids (PLA) is most widely used plastic which has found their applications in packaging of both short shelf life products like fresh fruits and vegetables and long shelf life products like potato chips and pasta (Jabeen et.al, 2015). Edible vaccines have received considerable attention from researchers in both academia and industry. Charles Arntzen (who was the first to use the phrase "edible vaccine"), with Hugh Masonand colleagues have pioneered the field with work on hepatitis $B$ and heat labile toxin, B subunit,in tobacco plants and potato tubers. Edible vaccines have been shown to induce good mucosal immune responses (Sibila et.al.,2005). The advantages of developing vaccines in plants are the absence of contamination risk, inexpensive, large scale production and most importantly the option of producing edible vaccines. The threat of bio-terrorism can also be eliminated in producing plant vaccines (Doddamane et.al, 2018). It is eveident that, vaccines are ,most widely used thorughout the world to minimize the rate of mortality in caused by infectious organisms. But, they have some adverse reactions on some individuals. Edible vaccines can be one of the alternatives of the traditional vaccines as they can overcome the problems associated with traditional vaccines. Edible vaccines can be produced by inserting a desired gene that codes for an antigen isolated from the microbes in to plant by one to different methods. A virus, bacterium or any other suitable vector can be used for the experiment (Joshi et.al, 2011). It can also achieved by biolistic or electroporation method. Some opf advantages of edible vaccines on traditional vaccines are their effective and targeted delivery, elicit mucosal immunuty, cost effective in storage, their easy availability, etc. Now a days they are being used to cure gastrointestinal disorders, maleria, measles, rabies, hepatitis B, HIV and Chloera. Edible vaccine can be produced in plants like rice, wheat, tobacco, soyabean, lettuce, potato, banana etc (Nayik et.al., 2016). Edible plant derived vaccines may lead to a future of safer and more effective immunization. They have passed the major hurdles in the path of emerging vaccine technology. This technology would be useful in future for the complex diseases like HIV, maleria etc with which the scientific community still strruggling (Lal et. al, 2007).

\section{NEGETIVE ROLE OF BIOTECHNOLOGY -}

Margherita (2016), Published a article on potential risks of genetically modified organisms. According to him genetically modiefied organisms though have some advantages, also have some disadvantages. It 
is evident that, GMos arises some issues like high prices of patented seeds which have some obligation and prohibition of the traditional practices of saving seeds from previous seasosns. This rule creates significant socioeconomic and cultural dilemma among farmers. GMOs are also responsible in drastic reduction in crop diversity ins the countries like USA, Canada, Argentina and Brazil. It is thought that, GMOs met the problem of hunger nad poverty, but according to Margherita, GMOs failed to do so. GMOs also harnessed rules and regulations of patenting and intellectual property rights.

A critical review on the promise and problems of GM foods have been published by Chen Zhang et.al (2016). They summerized some benefits and potential problems of GM foods. According to them, genetically modified foods are uncertainly affects on human health and environment. Consumer are in anxiety regarding the less knowledge about biological techniques involved in the development, improper dissemination, ethical principles and adequacy of evaluation of genetically modiefied food. There thre major risks of GM foodson health, including toxicity, allergenicity and genetic hazards which arise from three potential sources, the inserted gene and their expressed proteins, secondary or pleiotropic effects of the products of gene expression and the possible disruption of natural genes, in the manupulated organism. GM foods are also grounds some ecological risks including developed resistance by pest, weed and insect towards the pesticides, weedicides and insecticides respectively. Overuse of chemical pesticides and insecticides kills major types of pests which results in the increased number of minor pests. This shift may be responsible for the shifting of pests from genetically engineered plants to nonengineered undauted species. This change finally disrupts entire food chain. Overuse of antibodies in medical science gradually develops resistance in pathogenic bacteria against antibiotics.

GM foods may effectes allergic reactions, not fully environment friendly, affects biodiversity by dynamic changes in food chains and Decreases antibiotic efficacy. They may have unusaual and unnatural taste, partially unsafe to consume, rises conflicts, can be misused as a weapon by enemies, give rise new diseases and somewhat costly than traditional foods (Mathur, 2018).

Key et. al., 2008, carried out a study on GM plants and concluded that, GM foods are not harmful to human health, because according to him millions of people consuming such foods have not shown any types of ill effects. However, potential toxicity of the protein expressed in a GM food should be assessed. Also, potential allergenicity to the novel gene product also checked thorugh analytical tests. Because some GM foods can show allergic effects of human health. The allergic effects of GM foods can be screened by using some model animals like mouse.Genetically engineered forest trees have some potential environmental risks which cause economic and social loss. The scientific studies undertaken by scientists reveals that genetically modified forest tress has some side effects like transgene spreading by horizontal gene transfer which are responsible for becoming many exotic plants weedy. Enginnered sterility, hazards of resistant biotypes and altered multi-trophic processes causes negetive impact on ecosystem( (Mathew and Campbell, 2000).Ania (2003), has enlisted some potential risks of agricultural biotechnology which includes, some health related issues (Allergic and toxic nature of GM crops,antibiotic resistance), some environmental issues (Potential gene escape and superweeds, impacts on nontarget 
species,inscecticide resistance and loss of biodiversity) and some social issues (safety and regulation of GM foods). Bioplastics are the new biotechnological invention derived from biological resources is most significant and safe than the conventional plastics. People now started relay and use bioplastics but facing some problems which can be overcome by some efforts. Some disadvantages of bioplastics are, misconceptions, higher costs as compare to conventional plastics, Recycling of different types of bioplastics is not possible, no government support and limited supply of chemicals etc. (Pankaj kumar and Sonia, 2016) and lack of legislation (Ezgi and Havva, 2015).Edible vaccines could have a best alternative to traditional vaccines which causes some adverse effects in some individuals. But edible vaccines which are produced in some plants may have some disadvantages like, possibility of development of immunotolerance to the vaccine protein of peptide, cosistency of the dosage differes from plant to plant, generation to generation, protein content, patients age, weight etc. Stability of vaccine also differs from plant to plant. Some foods containing edible vaccines like potato cannot be eaten raw and needs to cook can denature vaccines. Vaccine fruit and normal fruit cannot be differentiated which may cause misadministration of vaccine which could lead to tolerance (Joshi et. al., 2011).

\section{CONCLUSION:}

Biotechnology has successfully established its way through the many needs of human being. It is widely being used to fulfill all the basic requirements of human being including food, medicine, agriculture, health and so on. Genetically modified plants are proved to be boon to fullfill all the needs of growing population. In agriculture, GM crops are very supreior than traditional crops in respect to disease and stress resistance, nutrition and yield. Bioplastic is very fruitful discovery of biotechnology which will be responsible to control ever increasing plastic pollution. Edible vaccines have the ability to overcome the drawbacks of traditional vaccines. Not only this, different biotechnological inventions in texile, industry, food, enzyme technology and pharmaceuticals have played very crucial role in the welfare of human being. Still biotechnological products have some disadvantages too. GM foods though, increased yield, and nutritional potential of plants, it shows some negetive effects like allergey to some individuals. In agriculture increased pest resistance, disturbance in food chain, uncertainty of GM corps are some issues related to environment. The products like bioplastics have some disadvantages like recycling, high cost and limited supply. Edible vaccines though a boon for medical science, it also has raised some issues like consistancy of dosage and changing nature with different plants. But the intensity of advantages is more than the disadvantages. Some negetive effects can be easily overcome by wide research in the field.

\section{REFERENCES}

Margherita A. (2016), Spread and potentail risks of Genetically Modiefied Organisms, Agriculture and Agricultureal Science Procedia, 8: 552559.

Chen Zhang, Robert W. and Han Shang (2016), Genetically modified foods: A criticalreview of their promise and problems, Food Science and Human welfare, 5: 116-123.

Mathur R. (2018), Genetic engineering and biosafety in the use of genetically modified foods, International $\mathrm{J}$. 
Advanced Scientific Research and Management, Special issue: 76-82.

Wim and Erik (2006), The impact if industrial biotechnology, J. Biotechnology, 1: 756-769.

Key S., Ma JKC and Drake PMW (2008), Genetically modified plants and human health, J. Royal Scoiety of Medicine, 101:290-298.

Mathews J.H. and M. M. Campbell (2000), The advantages and disadvantages of the application of genetic engineering to forest trees: a discussion, Forestry,73: 371- 380 .

Haroon and Mobeen (2016), Applications of food biotechnology, J. Ecosystem and Ecography, 6 (4):1-4.

Ania W. (2003), Use of biotechnology in agriculture- Benefits and risks, Biotechnology (revised), Cooperative extension ervice, CTAHR-May-2003.

Sanchez C. and C. Maria (2003), Biotechnology: Advantages and disadvantages for agriculture, Revista UDO Agricola, 3 (1): 1-11.

Pankaj kumar and Sonia (2016), Green Plastic: A new plastic for packaging, International J. engineering Science and Research technology, 5 (9): 168174.

Ezgi B.A. and Havva D.O. (2015), A review: Investigation of Bioplastics, J. Civil Engineering and Architecture, 9: 188192.

Jabeen N., Isharat M. and Gulzar A.N. (2015), Bioplastics and food packaging: A review, Cogent Food and Agriculture, 1: 01-06.

Ibrahim M.S., A.J Jafar, A.S.A. Shawai, S. Yusuf, M.Lateefah, I. Aminu (2017), Bioplastics as better alternative to Petroplastics and their role in National sustainability: A Review, Advances in
Bioscience and Bioengineering, 5 (4),63-70.

Joshi V.J. , C.P.Shah, M.N. Trivedi, U.D. Vachhani (2011), Edible vaccine: Abetter way for Immunization, International J. of Current Pharmaceutical Research, 3 (1): 53-56.

Nayik G.A., N.Jan, F.Shafi, O. Hameed, K. Muzaffar, S.M. Dar and I. Majid (2016), An Overview on Edible Vaccines and Immunization, Austin J. Nutrition and Food Sciences, 4 (2): 0105.

Sibila J., S. Mihajevic,N. Bauer (2005), Production of Biopharmaceuticals, Antibodies and Edible vaccines in transgenic plants, Current Studies of Biotechnology,Vol-IV- ImmunoModulatory Drugs: 121-127.

Doddamane M., S. Muneerappa, A. T. Narayanappa (2018), Production of therapeutic oral vaccines from transgenic plants- a promising way in treatment of diseases, International $\mathrm{J}$. Vaccines and Vaccination, 5 (3): 6367.

Lal P., V.G. Ramachandran, R.Goyal and R.Sharma (2007), Edible Vaccines: Current status and future, Indian $\mathrm{J}$. Medical Microbiology, 25 (2): 93-102. 